\title{
100 nm AlSb/InAs HEMT for Ultra-Low-Power Consumption, Low-Noise Applications
}

\author{
Cyrille Gardès, Sonia Bagumako, Ludovic Desplanque, Nicolas Wichmann, \\ Sylvain Bollaert, François Danneville, Xavier Wallart, and Yannick Roelens
}

\begin{abstract}
Institut d'Électronique de Microélectronique et de Nanotechnologie (IEMN), UMR CNRS 8520, Université Lille I, BP 60069, 59652 Villeneuve d’Ascq Cedex, France
\end{abstract}

Correspondence should be addressed to Cyrille Gardès; cyrille.gardes@iemn.univ-lillel.fr

Received 30 August 2013; Accepted 5 January 2014; Published 23 February 2014

Academic Editors: Y.-S. Lin, J. F. Paris, and J.-H. Park

Copyright (C) 2014 Cyrille Gardès et al. This is an open access article distributed under the Creative Commons Attribution License, which permits unrestricted use, distribution, and reproduction in any medium, provided the original work is properly cited.

\begin{abstract}
We report on high frequency (HF) and noise performances of AlSb/InAs high electron mobility transistor (HEMT) with $100 \mathrm{~nm}$ gate length at room temperature in low-power regime. Extrinsic cut-off frequencies $f_{T} / f_{\max }$ of 100/125 GHz together with minimum noise figure $\mathrm{NF}_{\text {min }}=0.5 \mathrm{~dB}$ and associated gain $G_{\text {ass }}=12 \mathrm{~dB}$ at $12 \mathrm{GHz}$ have been obtained at drain bias of only $80 \mathrm{mV}$, corresponding to $4 \mathrm{~mW} / \mathrm{mm}$ DC power dissipation. This demonstrates the great ability of AlSb/InAs HEMT for high-frequency operation combined with low-noise performances in ultra-low-power regime.
\end{abstract}

\section{Introduction}

Though the best high frequency performances are obtained for InAlAs/InGaAs HEMT technology which is more mature [1], AlSb/InAs HEMTs are potentially excellent candidates for low-voltage, low-power consumption operation in the case of high-speed analog and digital applications [2]. AlSb/InAs heterostructures are grown since the 1980s [3, 4], but AlSb/InAs HEMT with noticeable RF figures-of-merit and amplifiers with interesting low-noise performances have only been obtained since the last ten years $[5,6]$.

The best extrinsic $f_{T}$ of $303 \mathrm{GHz}$ has been reached for a transistor with $120 \mathrm{~nm}$ gate length at drain bias of $0.44 \mathrm{~V}$ [7]. The main modifications regarding our previous work $[7,8]$ lie in an optimization of heterostructure growth conditions [9], no ohmic cap layer [10], and the use of alternative metallic gate stack [11]. With this technology, the highest combination of cut-off frequencies obtained simultaneously for AlSb/InAs HEMTs has recently been shown at $V_{d s}=360 \mathrm{mV}$ [10], beyond previous $f_{T} / f_{\max }$ record of $260 / 280 \mathrm{GHz}$ reported for $100 \mathrm{~nm}$ HEMT at $V_{d s}=400 \mathrm{mV}$ [12]. Cut-off frequencies $f_{T} / f_{\max }$ of $290 / 335 \mathrm{GHz}$ were obtained for a $120 \mathrm{~nm}$ HEMT. We presently focus on HEMT operation in mobility regime $\left(V_{d s}=80 \mathrm{mV}\right)$ in which we will demonstrate that no impact ionization occurs. In these low drain bias conditions, corresponding to ultra-low-power dissipation, previous works report $f_{T} / f_{\max }$ of $112 / 107 \mathrm{GHz}$ for $\left(V_{d s}=0.1 \mathrm{~V} ; P_{\mathrm{DC}}=\right.$ $4.3 \mathrm{~mW} / \mathrm{mm})[5]$ and $f_{T} / f_{\max }$ of $143 / 115 \mathrm{GHz}$ at $\left(V_{d s}=0.1 \mathrm{~V}\right.$; $P_{\mathrm{DC}}=9.9 \mathrm{~mW} / \mathrm{mm}$ ) [7]. In this study, we present a full set of characteristics at $V_{d s}=80 \mathrm{mV}$ regarding DC, HF, and noise performances, extracting RF figures-of-merit, extrinsic and intrinsic parameters, and noise parameters obtained from small-signal equivalent circuit with noise sources.

\section{Heterostructure and Device Fabrication}

2.1. Heterostructure. The AlSb/InAs heterostructure was grown by molecular beam epitaxy on 3-inche semi-insulating GaAs substrate. A thick AlSb buffer is used to accommodate the large lattice mismatched between $6.1 \AA$ materials and GaAs substrate. Then, the structure consists of a $120 \AA$ InAs channel, a $65 \AA$ AlSb spacer, a Te $\delta$-doping plane, and a composite Schottky barrier with a $25 \AA \mathrm{Al}_{0.8} \mathrm{Ga}_{0.2} \mathrm{Sb}$ layer and a $50 \AA \mathrm{Al}_{0.5} \mathrm{In}_{0.5}$ As layer (Figure 1). The $\mathrm{Al}_{0.5} \mathrm{In}_{0.5} \mathrm{As}$ layer in the composite Schottky barrier avoids oxidation of $\mathrm{Al}_{0.8} \mathrm{Ga}_{0.2} \mathrm{Sb}$ with air exposure and acts as a hole barrier [13]. Hall measurements at room temperature exhibit a sheet 


\begin{tabular}{ccc}
\hline Protection layer & $\mathrm{Al}_{0.5} \mathrm{In}_{0.5} \mathrm{As}$ & $50 \AA$ \\
Barrier layer & $\mathrm{Al}_{0.8} \mathrm{Ga}_{0.2} \mathrm{Sb}$ & $25 \AA$ \\
$\delta$-doping plane & $\mathrm{Te} 4.5 \times 10^{12} \mathrm{~cm}^{-2}$ & \\
\hline Spacer layer & $\mathrm{AlSb}$ & $65 \AA$ \\
Channel layer & $\mathrm{InAs}$ & $120 \AA$ \\
Buffer layer & $\mathrm{AlSb}$ & $500 \AA$ \\
Buffer layer & $\mathrm{Al}_{0.8} \mathrm{Ga}_{0.2} \mathrm{Sb}$ & $2500 \AA$ \\
Buffer & $\mathrm{AlSb}$ & $15000 \AA$ \\
S.I. substrate & $\mathrm{GaAs}$ & \\
\hline
\end{tabular}

Figure 1: AlSb/InAs heterostructure.

carrier density of $1.5 \times 10^{12} \mathrm{~cm}^{-2}$ and electron mobility of $26000 \mathrm{~cm}^{2} /(\mathrm{Vs})$, giving sheet resistance of $160 \Omega / \square$.

2.2. Device Fabrication. HEMTs fabrication starts with ohmic contact evaporation of $\mathrm{Pd} / \mathrm{Pt} / \mathrm{Au}$ after e-beam lithography, followed by rapid thermal annealing at $275^{\circ} \mathrm{C}$. Despite the absence of highly doped cap layer in the heterostructure, contact resistance, obtained by transmission-line model measurements, is still below $0.05 \Omega \cdot \mathrm{mm}$. Schottky T-gate is realized using bilayer resist e-beam lithography process and $\mathrm{Mo} / \mathrm{Pt} / \mathrm{Au}$ metallization. Then, Ti/Au bonding pads are evaporated. Finally, the active area is defined by chemical deep mesa isolation using $\mathrm{HF} / \mathrm{H}_{2} \mathrm{O}_{2}$ solution to completely remove the AlSb buffer, leading to air-bridge gate. Device features are a two-finger $100 \mathrm{~nm}$ long gate with $2 \times 25 \mu \mathrm{m}$ transistor width (Figure 2). Source-drain spacing is $1.2 \mu \mathrm{m}$.

\section{Static and Dynamic Measurements}

Drain current-voltage characteristics are plotted in Figure 3. Pinch-off voltage is $-1.0 \mathrm{~V}$. Maximum drain currents are $220 \mathrm{~mA} / \mathrm{mm}$ and $620 \mathrm{~mA} / \mathrm{mm}$ for drain bias of $80 \mathrm{mV}$ and $240 \mathrm{mV}$, respectively. These are similar to our previous results $[7,8]$ despite the higher sheet resistance of the heterostructure and the higher source-drain spacing in the present device.

HF measurement setup consists in a $67 \mathrm{GHz}$ Agilent PNA for $S$-parameters on-wafer measurements and an Agilent HP4142 generator for DC biasing. Extrinsic current gain $\left|H_{21}\right|^{2}$ and unilateral power gain $U$ for $V_{d s}=80 \mathrm{mV}$ and $V_{d s}=240 \mathrm{mV}$ at peak $f_{T}$ are presented in Figure 4. Cutoff frequencies $\left(f_{T}, f_{\max }\right)$ obtained simultaneously at $V_{d s}=$ $80 \mathrm{mV}$ are $(108 \mathrm{GHz}, 129 \mathrm{GHz})$ for power dissipation $P_{\mathrm{DC}}=$ $5 \mathrm{~mW} / \mathrm{mm}$ and $(232 \mathrm{GHz}, 250 \mathrm{GHz})$ at $V_{d s}=240 \mathrm{mV}$ for $P_{\mathrm{DC}}=60 \mathrm{~mW} / \mathrm{mm} . P_{\mathrm{DC}}$ is calculated as $V_{d s} \times I_{d s}$, with power consumption in the gate being negligible.

In Figure 5, the evolution of extrinsic cut-off frequencies is plotted as a function of $P_{\mathrm{DC}}$ for $V_{d s}=80 \mathrm{mV}$ and $V_{d s}=$ $240 \mathrm{mV}$. This evidences the ability of AlSb/InAs HEMT for RF performances in low drain bias regime. In fact, $\left(f_{T}, f_{\max }\right)$ are $(100 \mathrm{GHz}, 125 \mathrm{GHz})$ for $P_{\mathrm{DC}}=4 \mathrm{~mW} / \mathrm{mm}$ at $V_{d s}=80 \mathrm{mV}$. The DC power consumption at $V_{d s}=240 \mathrm{mV}$ for reaching the same cut-off frequencies is, respectively, $30 \mathrm{~mW} / \mathrm{mm}$ and $22 \mathrm{~mW} / \mathrm{mm}$. Consequently, to get the same RF performances in more standard drain bias conditions, power consumption must be at least 5 times higher.

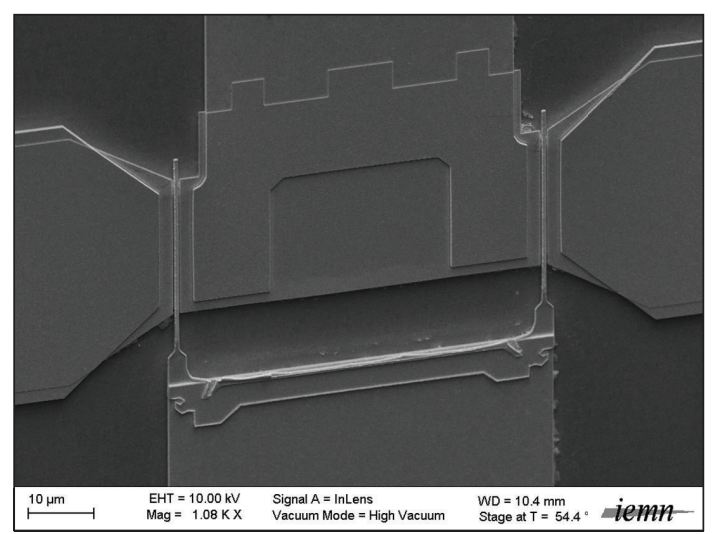

Figure 2: $100 \mathrm{~nm}$ AlSb/InAs HEMT.

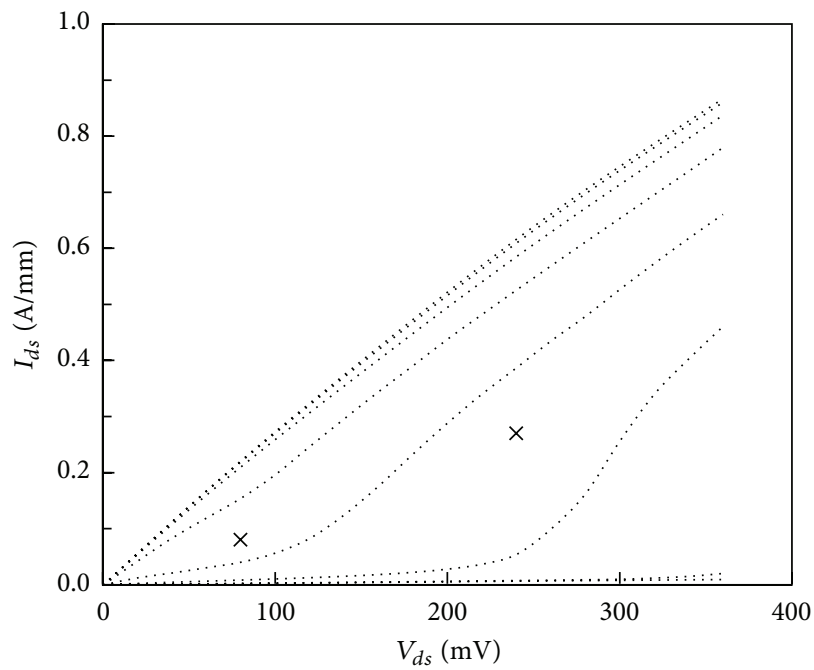

FIGURE 3: Drain current-voltage characteristic of $100 \mathrm{~nm}$ AlSb/InAs HEMT. $V_{g s}$ is varying from $0 \mathrm{~V}$ to $-1.4 \mathrm{~V}$ with $-0.2 \mathrm{~V}$ step. (Crosses are polarisation conditions for measurements at peak $f_{T}$ ).

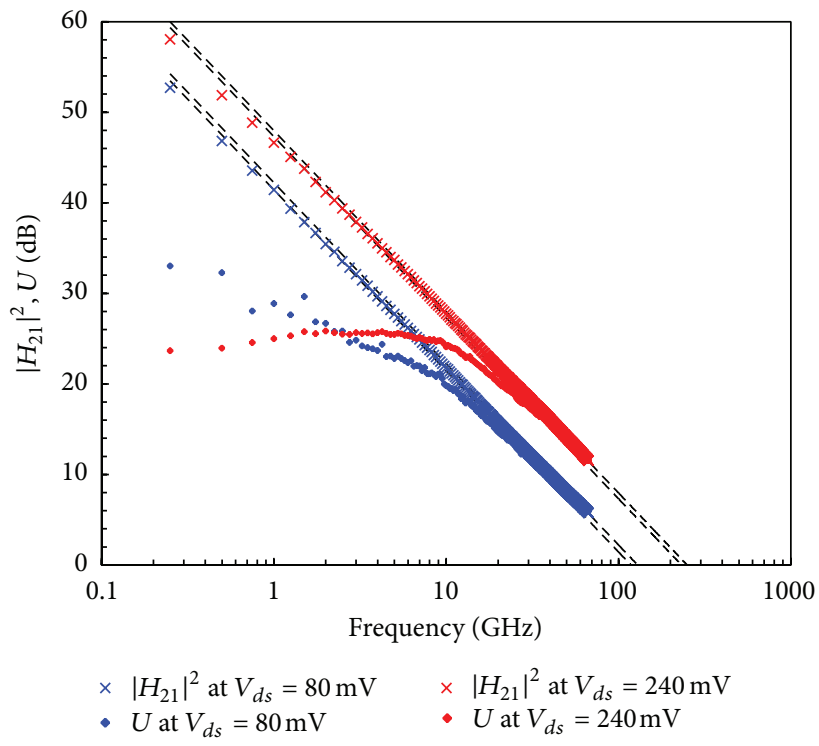

Figure 4: $f_{\max }$ and $f_{T}$ extrapolated from Mason's unilateral gain $U$ and current gain $\left|H_{21}\right|^{2}$ for $V_{d s}=80 \mathrm{mV}$ and $V_{d s}=240 \mathrm{mV}$. 
TABLE 1: Small-signal equivalent circuit parameters for $V_{d s}=80 \mathrm{mV}$ and $V_{d s}=240 \mathrm{mv}$ at peak $f_{T}$.

\begin{tabular}{lccccccccc}
\hline$V_{d s}(\mathrm{mV})$ & $R_{G}(\Omega / \mathrm{mm})$ & $R_{D}(\Omega \cdot \mathrm{mm})$ & $R_{S}(\Omega \cdot \mathrm{mm})$ & $g_{m}(\mathrm{~S} / \mathrm{mm})$ & $g_{d}(\mathrm{~S} / \mathrm{mm})$ & $C_{g s}(\mathrm{fF} / \mathrm{mm})$ & $C_{g d}(\mathrm{fF} / \mathrm{mm})$ & $g_{m 2}(\mathrm{~S} / \mathrm{mm})$ & $R_{g g}(\mathrm{k} \Omega)$ \\
\hline 80 & 74 & 0.11 & 0.11 & 0.75 & 0.73 & 468 & 327 & 0.007 & 80 \\
240 & 74 & 0.11 & 0.11 & 1.36 & 0.72 & 584 & 259 & 1.47 & 12 \\
\hline
\end{tabular}

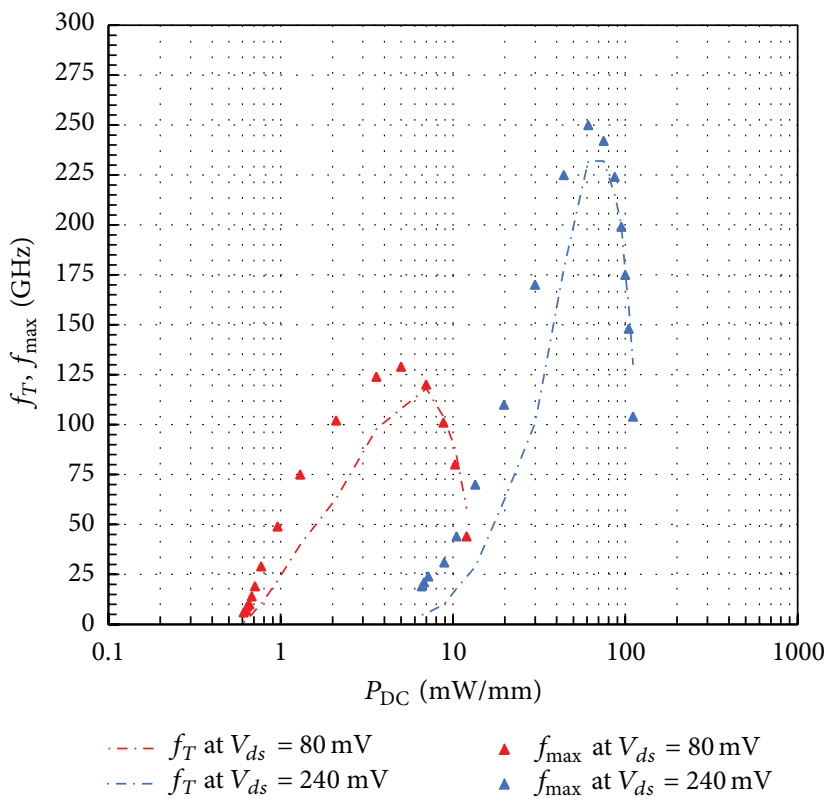

FIgURE 5: Extrapolated $\left(f_{T}, f_{\max }\right)$ plotted as a function of DC power consumption calculated as $V_{d s} \times I_{d s}$.

Finally, intrinsic and extrinsic parameters have been extracted from the small-signal equivalent circuit (SSEC) presented in Figure 6.

Resistance $R_{g g}$ parallel to $C_{g s}$ and current source $g_{m 2}$ parallel to output conductance $g_{d}$ to account, respectively, for gate leakage current and impact ionization have been added to the classical model. Indeed, there is impact ionization in $\mathrm{AlSb} / \mathrm{InAs}$ HEMT at high drain bias with an increase of gate current and a typical bell-shape of the $I_{g s}-V_{g s}$ characteristic [14], which is a signature of impact ionization in DC measurements. With RF characterization, impact ionization results in $S_{22}$ parameter evolving from inductive to capacitive behaviour with increasing frequency as can be seen for $V_{d s}=240 \mathrm{mV}$ in Figure 7. In the literature, this phenomenon in HEMTs has been modelised with a low-pass filter [15]. We prefer to introduce an additional current source $g_{m 2}$ controlled by gate-drain voltage as realized by Isler [16] to account for impact ionization effects. This model allows to perfectly fit scattering parameters at $V_{d s}=80 \mathrm{mV}$ and $V_{d s}=$ $240 \mathrm{mV}$ as shown in Figure 7.

Parameters extracted from the SSEC at peak $f_{T}$ are presented in Table $1 . R_{g g}$ is much higher at $V_{d s}=80 \mathrm{mV}$ compared to $V_{d s}=240 \mathrm{mV}$, which is relevant of much lower gate leakage current, and $g_{m 2}$ is negligible at $V_{d s}=80 \mathrm{mV}$, which stresses that there is no impact ionization at this drain voltage.

\section{Noise Measurements}

Regarding low impact ionization occurring at $V_{d s}=80 \mathrm{mV}$ as shown above with RF wideband measurements, SSEC with noise sources as presented in Figure 8 is used. For the sake of simplicity, there is no current source accounting for impact ionization since extracted value of $g_{m 2}$ at $V_{d s}=$ $80 \mathrm{mV}$ is negligible. As a consequence, no additional noise source, which should probably be correlated with output noise current or even input noise voltage, is required for extraction of accurate parameters values. We extracted the following noise parameters using $F_{50}$ method [17]: minimum noise figure $\mathrm{NF}_{\min }$, associated gain $G_{\text {ass }}$, noise equivalent resistance $R_{n}$, and output noise temperature $T_{\text {out }}$ at $12 \mathrm{GHz}$ (Figures 9 and 10). $\mathrm{NF}_{\min }$ is $0.5 \mathrm{~dB}$ and $G_{\text {ass }}$ is $12 \mathrm{~dB}$ for $4 \mathrm{~mW} / \mathrm{mm}$ power dissipation. As a comparison, we should quote results obtained by Ma et al. [5] for $2 \times 20 \mu \mathrm{m}$ HEMT with $\mathrm{NF}_{\min }$ above $0.5 \mathrm{~dB}$ at $12 \mathrm{GHz}$ in the "best bias conditions for minimum noise figure." The present results should also be compared with similar $\mathrm{NF}_{\min }$ and $G_{\text {ass }}$ reported in literature for AlSb/InAs HEMTs but with 50\% higher DC power consumption of $6 \mathrm{~mW} / \mathrm{mm}$ at $V_{d s}=200 \mathrm{mV}[6,18]$. In the present case, at $V_{d s}=80 \mathrm{mV}, \mathrm{NF}_{\text {min }}$, and $G_{\text {ass }}$ are optima for $P_{\mathrm{DC}}=4 \mathrm{~mW} / \mathrm{mm}$ and it is important to underline that it would be impossible to reach these noise performances at 


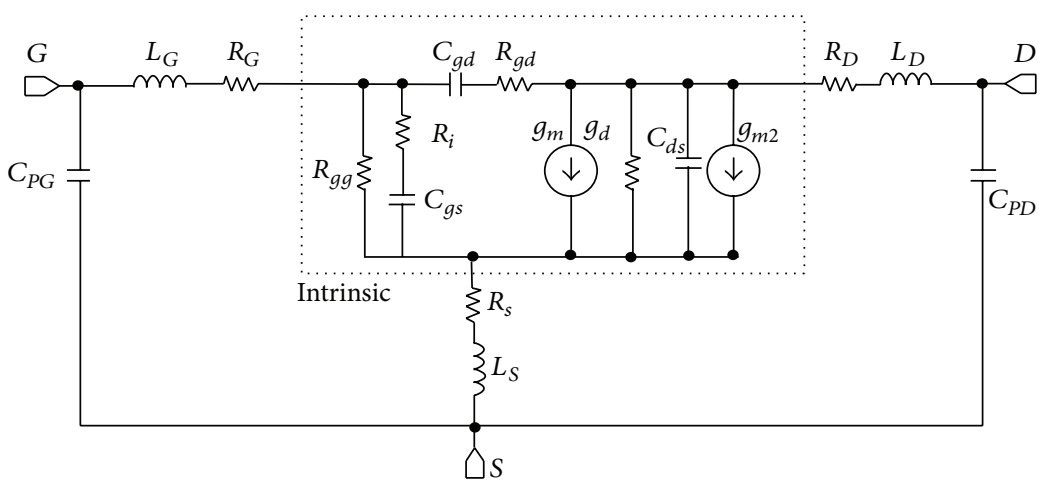

FIGURE 6: Small-signal equivalent circuit tacking into account gate leakage current $\left(R_{g g}\right)$ and impact ionisation $\left(g_{m 2}\right)$.

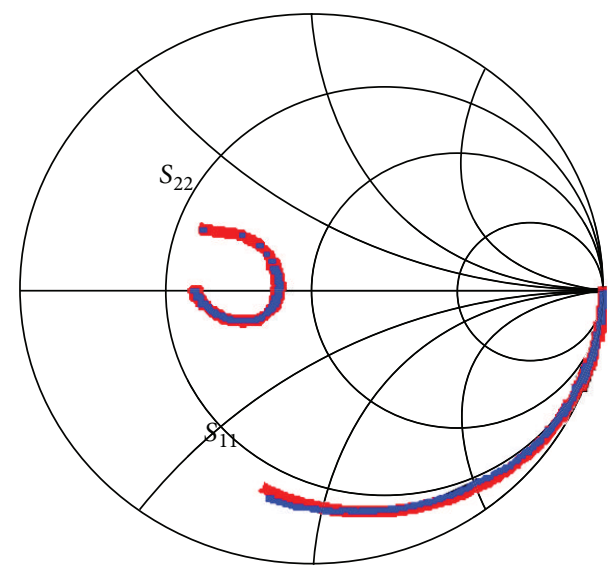

Freq $(250.0 \mathrm{MHz}$ to $67.00 \mathrm{GHz})$ $V_{d s}=240 \mathrm{mV}$

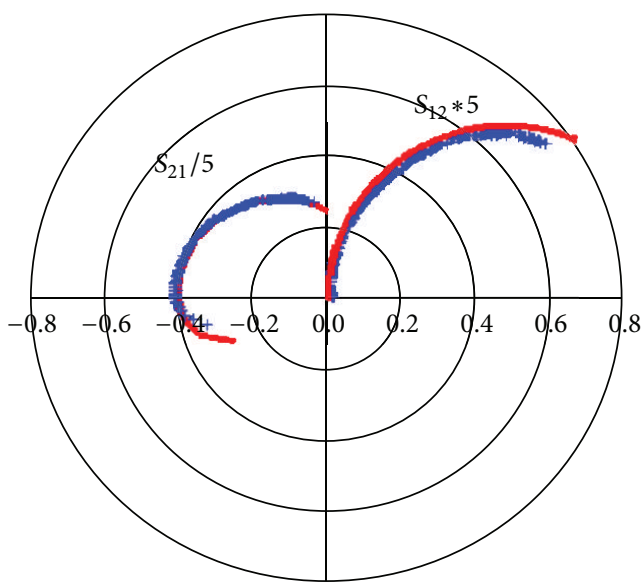

Freq (250.0 MHz to $67.00 \mathrm{GHz})$

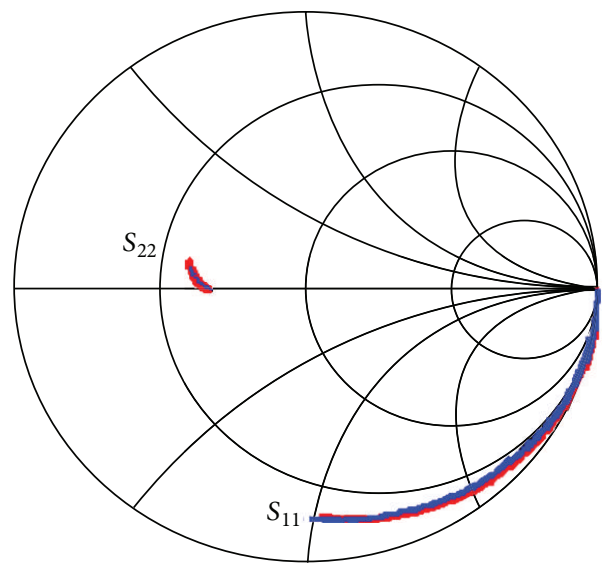

Freq $(250.0 \mathrm{MHz}$ to $67.00 \mathrm{GHz})$

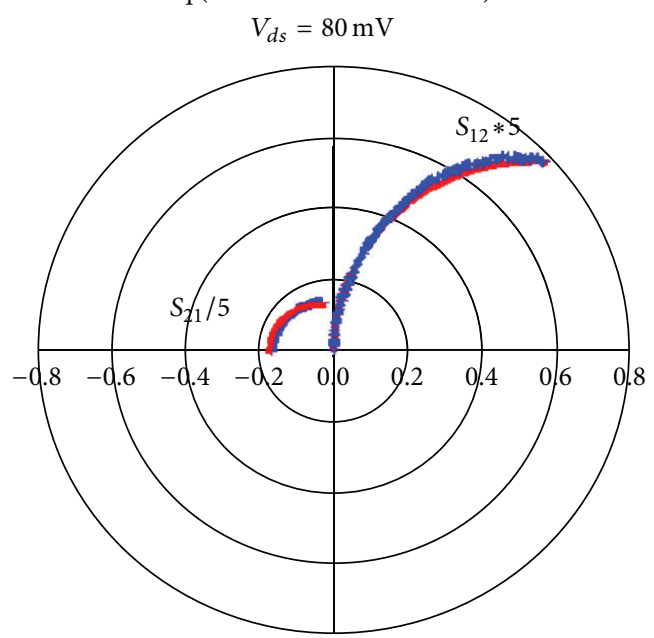

Freq $(250.0 \mathrm{MHz}$ to $67.00 \mathrm{GHz})$

FIGURE 7: S-parameters measured (blue dots) and simulated (red curves) at $V_{d s}=80 \mathrm{mV}$ and $V_{d s}=240 \mathrm{mV}$.

$V_{d s}=240 \mathrm{mV}$ with such low-power consumption. Despite an accurate extraction of noise parameters under high drain bias is not done here, the element values would obviously be degraded due to the higher gate voltage required to operate in low-power regime, which would increase shot noise. Then, drain polarization of transistor at $V_{d s}=80 \mathrm{mV}$ allows an excellent compromise between noise performances and power dissipation.

\section{Conclusion}

In this study, we reported on microwave and noise performances in low-power regime of AlSb/InAs HEMTs with optimized heterostructure. Combined $\left(f_{T}, f_{\max }\right)$ of $(100 \mathrm{GHz}, 125 \mathrm{GHz})$ have been obtained at $V_{d s}=80 \mathrm{mV}$ and DC power consumption of $4 \mathrm{~mW} / \mathrm{mm}$, performances that cannot be reached at $V_{d s}=240 \mathrm{mV}$ for such a low 


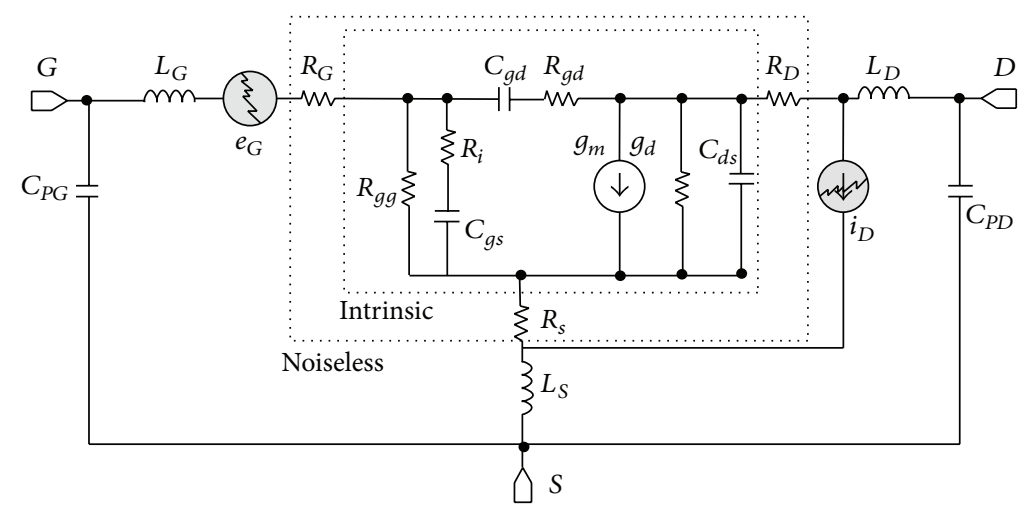

FIGURE 8: Small-signal equivalent circuit with noise sources for AlSb/InAs HEMT at $V_{d s}=80 \mathrm{mV}$.

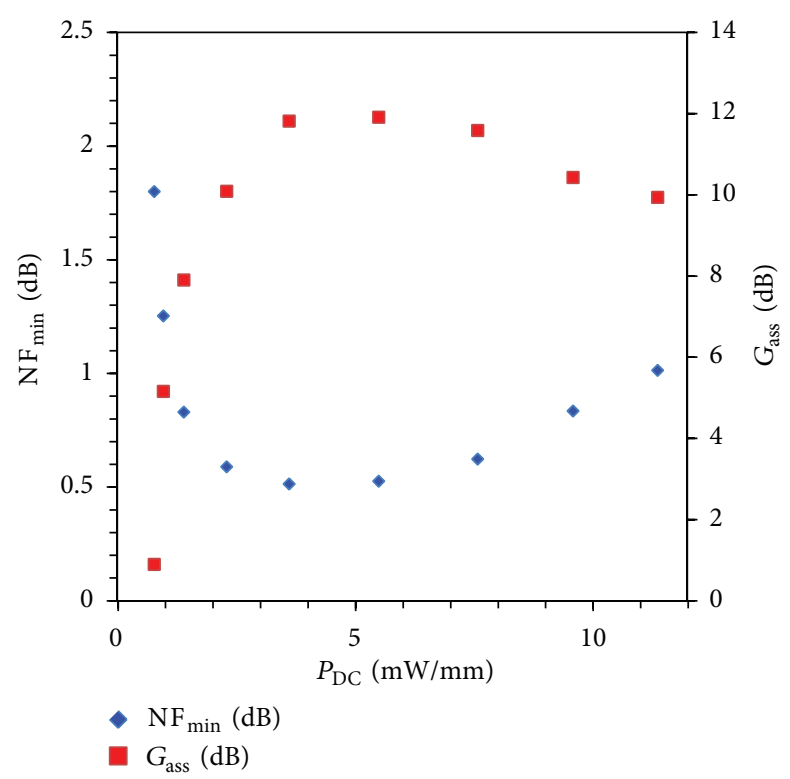

Figure 9: Minimum noise figure $\mathrm{NF}_{\text {min }}$ and associated gain $G_{\text {ass }}$ as a function of power consumption at $12 \mathrm{GHz}$ for $V_{d s}=80 \mathrm{mV}$.

power dissipation. A small-signal equivalent circuit was established and demonstrated that impact ionization effects at $V_{d s}=80 \mathrm{mV}$ are negligible, which is not the case for $V_{d s}=240 \mathrm{mV}$. This allowed an accurate extraction of noise parameters thanks to SSEC with noise sources fully reliable in mobility regime. $\mathrm{NF}_{\min }=0.5 \mathrm{~dB}$ and $G_{\text {ass }}=12 \mathrm{~dB}$ have been obtained at $12 \mathrm{GHz}$ for $\left(V_{d s}=80 \mathrm{mV} ; P_{\mathrm{DC}}=4 \mathrm{~mW} / \mathrm{mm}\right)$. These results exhibit the high suitability of AlSb/InAs HEMTs for combined RF and low-noise performances in ultra-low-power dissipation regime.

\section{Conflict of Interests}

The authors declare that there is no conflict of interests regarding the publication of this paper.

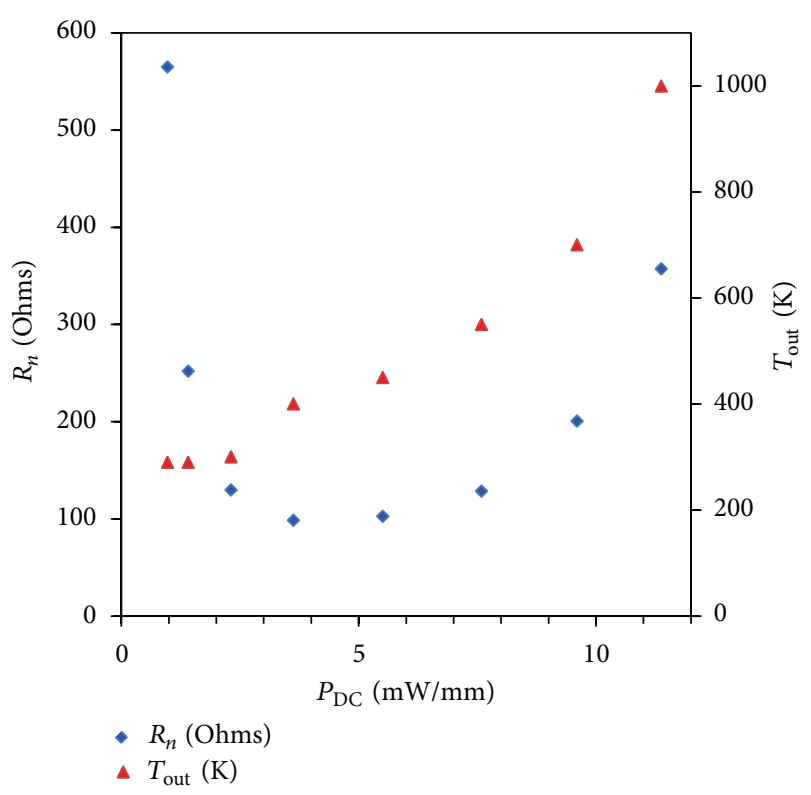

Figure 10: Noise equivalent resistance $R_{n}$ and output noise temperature $T_{\text {out }}$ as a function of power consumption at $12 \mathrm{GHz}$ for $V_{d s}=80 \mathrm{mV}$.

\section{Acknowledgments}

This work is supported by the National Research Agency under Projects Low IQ (no. ANR-08-NANO-022) and SMIC (no. ANR-11-ASTR-031-03).

\section{References}

[1] W. Deal, X. B. Mei, K. M. K. H. Leong, V. Radisic, S. Sarkozy, and R. Lai, "THz monolithic integrated circuits using InP high electron mobility transistors," IEEE Transactions on Terahertz Science and Technology, vol. 1, no. 1, pp. 25-32, 2011.

[2] B. R. Bennett, R. Magno, J. B. Boos, W. Kruppa, and M. G. Ancona, "Antimonide-based compound semiconductors for electronic devices: a review," Solid-State Electronics, vol. 49, no. 12, pp. 1875-1895, 2005. 
[3] C.-A. Chang, L. L. Chang, E. E. Mendez, M. S. Christie, and L. Esaki, "Electron densities in InAs-AlSb quantum wells," Journal of Vacuum Science \& Technology B, vol. 2, no. 2, pp. 214-216, 1984.

[4] G. Tuttle and H. Kroemer, "An AlSb/InAs/AlSb quantum well HFT," IEEE Transactions on Electron Devices, vol. 34, no. 11, p. 2358, 1987.

[5] B. Y. Ma, J. Bergman, P. Chen et al., "InAs/AlSb HEMT and its application to ultra-low-power wideband high-gain lownoise amplifiers," IEEE Transactions on Microwave Theory and Techniques, vol. 54, no. 12, pp. 4448-4454, 2006.

[6] W. R. Deal, R. Tsai, M. D. Lange, J. Brad Boos, B. R. Bennett, and A. Gutierrez, "A low power/low noise MMIC amplifier for phased-array applications using InAs/AlSb HEMT," in Proceedings of the IEEE MTT-S International Microwave Symposium Digest, pp. 2051-2054, June 2006.

[7] Y. Roelens, A. Olivier, L. Desplanque et al., "Tellurium $\delta$-doped $120 \mathrm{~nm}$ AlSb/InAs HEMTs: towards sub-100 mV electronics," in Proceedings of the 68th Device Research Conference (DRC '10), pp. 53-54, June 2010.

[8] A. Olivier, A. Noudeviwa, N. Wichmann et al., "High frequency performance of tellurium $\delta$-doped AlSb/InAs HEMTs at low power supply," in Proceedings of the 5th Microwave Integrated Circuits Conference (EuMIC '10), pp. 162-165, Paris, France, October 2010.

[9] L. Desplanque, S. El Kazzi, J. Codron -L et al., "AlSb nucleation induced anisotropic electron mobility in AlSb/InAs HEMTs heterostructures on GaAs," Applied Physics Letters, vol. 100, no. 26, pp. 262103-262104, 2012.

[10] C. Gardès, S. M. Bagumako, L. Desplanque et al., "120 nm $\mathrm{AlSb} / \mathrm{InAs} \mathrm{HEMT}$ without gate recess: $290 \mathrm{GHz} \mathrm{f}_{T}$ and $335 \mathrm{GHz}$ $\mathrm{f}_{\text {max }}$, in Proceedings of the International Conference on Indium Phosphide and Related Materials (IPRM '13), pp. 1-2, Kobe, Japan, 2013.

[11] Y. C. Chou, L. J. Lee, J. M. Yang et al., "The effect of gate metals on manufacturability of $0.1 \mu \mathrm{m}$ metamorphic AlSb/InAs HEMTs for ultra low-power applications," in Proceedings of the 20th International Conference on Indium Phosphide and Related Materials (IPRM '08), pp. 1-14, May 2008.

[12] R. Tsai, M. Lange, L. J. Lee et al., " $260 \mathrm{GHz} \mathrm{f}_{T}, 280 \mathrm{GHz} \mathrm{f}_{\max }$ AlSb/InAs HEMT technology," in Proceedings of the 63rd Device Research Conference (DRC '05), pp. 257-258, June 2005.

[13] J. Brad Boos, W. Kruppa, B. R. Bennett et al., "AlSb/InAs HEMT's for low-voltage, high-speed applications," IEEE Transactions on Electron Devices, vol. 45, no. 9, pp. 1869-1875, 1998.

[14] G. Moschetti, M. Abbasi, Per-Ake Nilsson et al., "True planar InAs/AlSb HEMTs with ion-implantation technique for lowpower cryogenic applications," Solid-State Electronics, vol. 79, pp. 268-273, 2013.

[15] C. Teyssandier, F. de Groote, R. Sommet et al., "Characterization and modeling of impact ionization effects on small and large signal characteristics of AlGaAs/GaInAs/GaAs PHEMTs," in Proceedings of the 3rd European Microwave Integrated Circuit Conference (EuMIC '08), pp. 119-122, Amsterdam, The Netherlands, October 2008.

[16] M. Isler, "Investigation and modeling of impact ionization in HEMTs for DC and RF operating conditions," Solid-State Electronics, vol. 46, no. 10, pp. 1587-1593, 2002.

[17] G. Dambrine, H. Happy, F. Danneville, and A. Cappy, "New method for on wafer noise measurement," IEEE Transactions on
Microwave Theory and Techniques, vol. 41, no. 3, pp. 375-381, 1993.

[18] R. Tsai, R. Grundbacher, M. Lange et al., "Manufacturable AlSb/InAs HEMT technology for ultra-low power millimeterwave integrated circuits," in Proceedings of the Mantech Conference, pp. 69-72, 2004. 

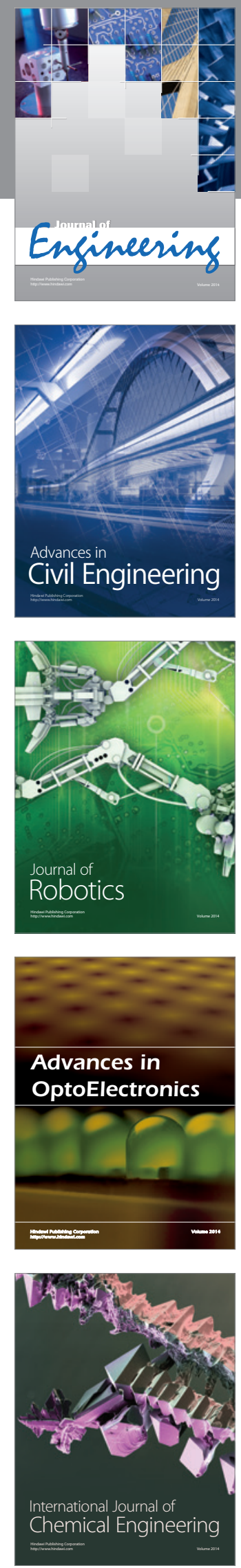

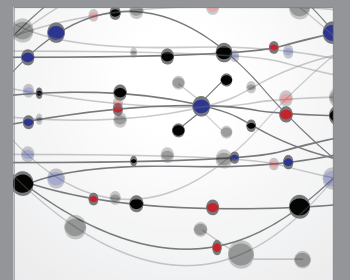

The Scientific World Journal
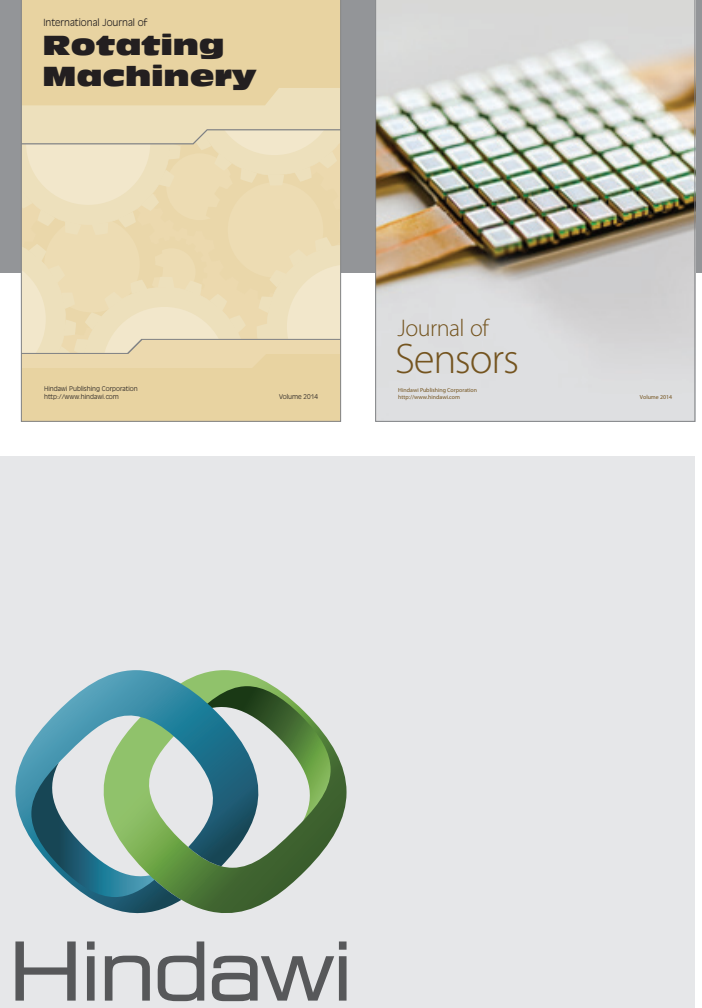

Submit your manuscripts at http://www.hindawi.com
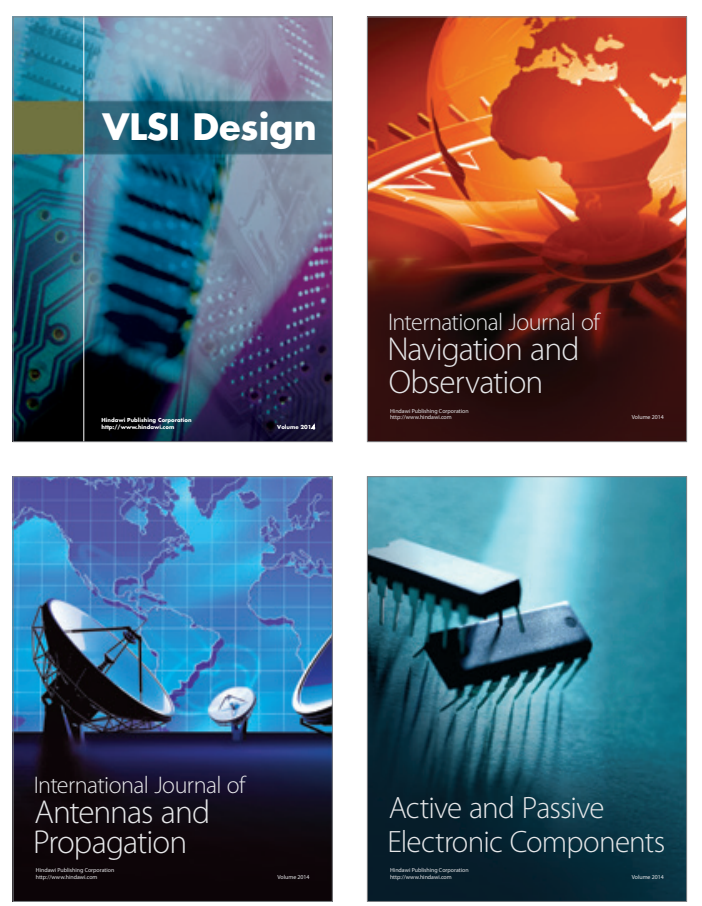
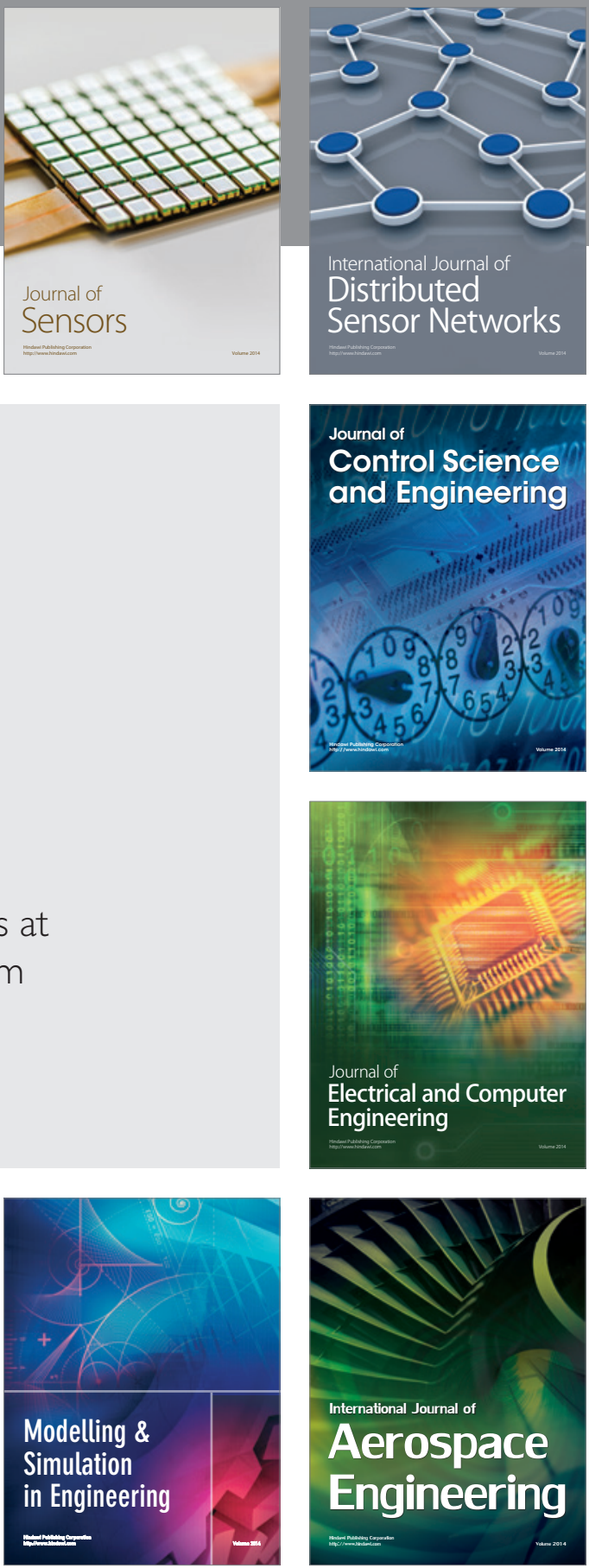

Journal of

Control Science

and Engineering
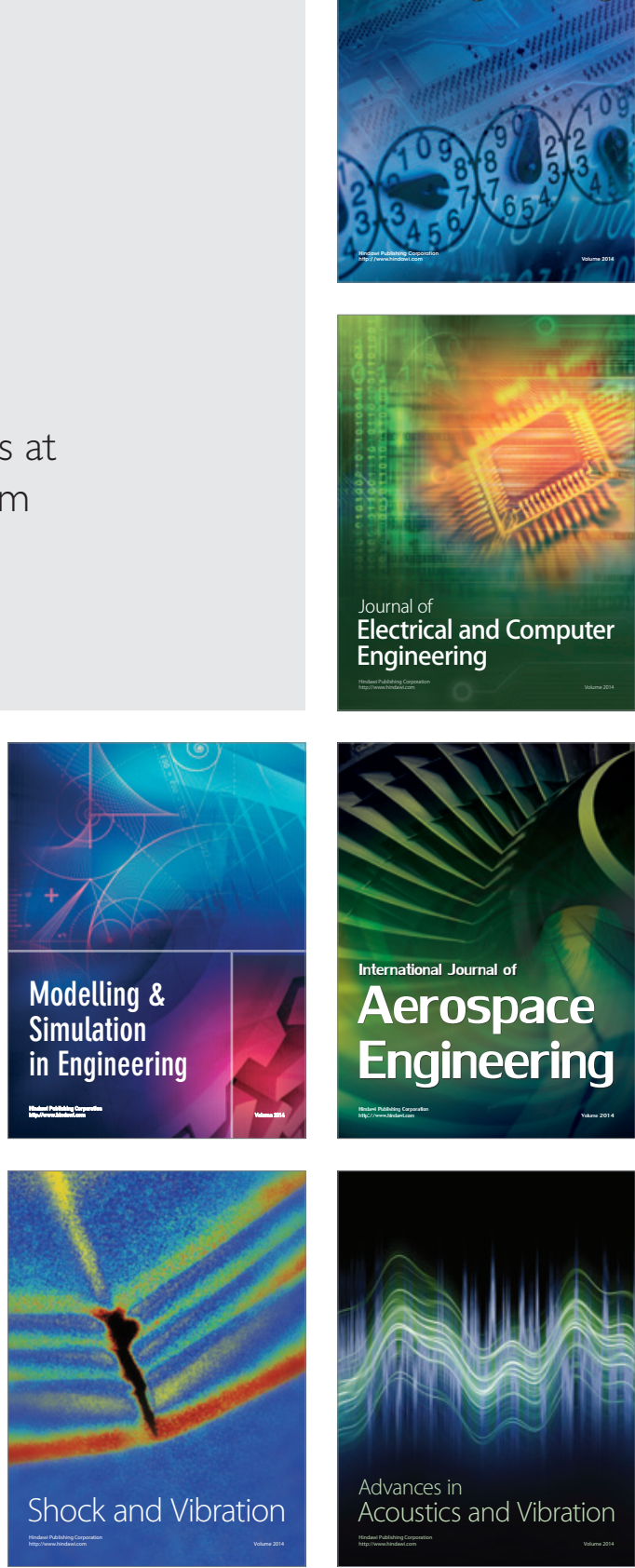